COMUNICAÇÃO CIENTÍFICA

\title{
PROPAGAÇÃO DA GOIABEIRA POR MINIESTAQUIA ${ }^{1}$
}

\author{
CLÁUDIA SALES MARINHO², LEONARDO MUNIZ AZIZ MILHEM³ ${ }^{3}$ JALILLE AMIMALTOÉ4 $^{4}$ \\ DEBORAH GUERRA BARROSO ${ }^{2}$, CELSO VALDEVINO POMMER $^{5}$
}

RESUMO - A miniestaquia é um método de propagação vegetativa muito utilizado na formação de minijardins clonais de Eucalyptus. Essa técnica poderia ser aplicada à multiplicação rápida de novos genótipos da goiabeira visando a dar suporte a trabalhos de melhoramento e, também, como tecnologia mais apropriada para uso em programas de produção de mudas certificadas. Este trabalho teve por objetivo avaliar a viabilidade da técnica da miniestaquia como método de propagação da goiabeira (Psidium guajava L.). Seedlings de goiabeira foram despontados aos 118 dias após semeadura e, com os despontes, foram preparadas 210 miniestacas com 13,5 mm a 37,9 mm de comprimento, colocadas para enraizamento em substrato comercial, em câmara de nebulização intermitente. Quarenta dias após o estaqueamento, verificou-se que 76\% das miniestacas enraizaram e emitiram parte aérea. As minitouceiras de goiabeira apresentaram média de 1,52 brotação por seedling despontado. Aos 39 dias após o desponte, foram preparadas miniestacas das rebrotas emitidas pelos seedlings. Trinta e cinco dias após o estaqueamento, essas miniestacas, com comprimento médio de 13,56 mm, apresentaram 100\% de enraizamento. Os resultados deste trabalho demonstram a viabilidade da miniestaquia para multiplicação rápida da goiabeira, o que pode auxiliar nos trabalhos de melhoramento em seleções preliminares de genótipos de interesse.

Termos para indexação: Psidium guajava, enraizamento de estacas, propagação vegetativa, fruticultura tropical, melhoramento genético.

\section{GUAVA PROPAGATION THROUGH MINICUTTINGS}

\begin{abstract}
Minicutting is a method of vegetative propagation widely used in the formation of clonal minigarden of Eucalyptus. This technique presents potential to be used for fast multiplication of new genotypes of guava, giving support to breeding work and, also, as a more appropriate technology for use in certified propagation programs. This study was carried out to evaluate the viability of the minicutting technique as a method of guava propagation (Psidium guajava L.). Seedlings of guava, 118 days after sowing, were detopped and from this blunt 210 minicuttings were prepared, $13.5 \mathrm{~mm}$ to $37.9 \mathrm{~mm}$ long, and placed in commercial substrata to rooting in intermittent mist chamber. Fourty days after, $76 \%$ of the minicuttings have rooted and emitted aerial part. The ministumps of guava presented average of 1.52 sprouts per blunted seedling. Minicuttings of regrowth were prepared from the seedlings, 39 days after blunt. Thirty-five days after been planted, these minicuttings, with average length of $13.56 \mathrm{~mm}$, presented $100 \%$ of rooting. Results demonstrated the viability of minicutting for fast multiplication of guava, which can give support to breeding works in preliminary selections of interesting genotypes.
\end{abstract}

Index terms: Psidium guajava, rooting cuttings, vegetative propagation, tropical horticulture, genetic improvement.

\footnotetext{
${ }^{1}$ (Trabalho 131-08). Recebido em: 27-05-2008. Aceito para publicação em: 24-10-2008.

${ }^{2}$ Professora da Universidade Estadual do Norte Fluminense 'Darcy Ribeiro' - UENF/CCTA/LFIT, Av. Alberto Lamego 2000, Horto, 28013-602, Campos dos Goytacazes-RJ, E-mail: marinho@uenf.br.

${ }^{3}$ Eng. ${ }^{\circ}$ Agr. ${ }^{\circ}$, UENF/CCTA/LFIT, E-mail: leomilhem@yahoo.com..br.

${ }^{4}$ Eng. ${ }^{a}$ Agr. ${ }^{\text {, }}$ Doutoranda em Produção Vegetal, UENF/CCTA/LFIT, E-mail: jalilleamim@yahoo.com.br.

${ }^{5}$ Eng. ${ }^{\circ}$ Agr. ${ }^{\circ}$, Dr., Professor Titular Visitante, UENF/CCTA/LMGV, E-mail: celso@uenf.br.
} 
O enraizamento de estacas de goiabeira (Psidium guajava) é dependente do seu grau de lignificação, do genótipo, de suas condições fisiológicas e de fatores ambientais. Dentro da mesma espécie, existem diferenças quanto à facilidade de enraizamento. O uso de estacas herbáceas em ambientes com umidade relativa alta, obtido por nebulização intermitente, além do emprego de reguladores de crescimento, tem sido a técnica mais empregada na propagação comercial da goiabeira (Zietemann \& Roberto, 2007).

Dentre as diversas técnicas que podem ser utilizadas para propagação vegetativa, a miniestaquia é alternativa que vem sendo bastante aplicada na propagação de espécies florestais, especialmente na cultura do eucalipto, e apresenta potencial para emprego em outras plantas da família Myrtaceae (Alfenas et al., 2004).

Na miniestaquia, os propágulos vegetativos são obtidos pela coleta de ápices caulinares emitidos por uma estaca enraizada pelo método tradicional de estaquia ou por mudas seminais, após desponte. A planta recepada emite novas brotações que, em intervalos variáveis, em função da época do ano, do clone/espécie e das condições nutricionais, são coletadas e postas a enraizar em condições controladas de temperatura e umidade. Dessa forma, a parte basal da planta despontada constitui uma minicepa, que fornecerá as brotações (miniestacas) para enraizamento e formação das futuras mudas (Andrejow, 2006). O conjunto de minicepas clonais é denominado minijardim clonal (Alfenas et al., 2004).

Segundo Xavier et al. (2003), a técnica da miniestaquia apresenta algumas vantagens em relação à estaquia, dentre as quais podem ser citadas a redução da área necessária para a formação do jardim miniclonal, por este localizar-se em bandejas no próprio viveiro; a redução dos custos de transporte e coleta das brotações; a maior eficiência das atividades de manejo no jardim miniclonal, quanto à irrigação, nutrição e controle de pragas e doenças, além de proporcionar maior qualidade, velocidade $\mathrm{e}$ percentual de enraizamento das miniestacas. Embora sendo Myrtaceae, como o eucalipto, não foram encontradas informações na literatura sobre a propagação da goiabeira pela técnica da miniestaquia.

Objetivou-se, com este trabalho, avaliar o enraizamento de miniestacas obtidas a partir de seedlings de goiaba 'Paluma' e o potencial de rebrota das plantas recepadas.

O trabalho foi conduzido no Centro de Ciências e Tecnologias Agropecuárias da Universidade Estadual do Norte Fluminense Darcy
Ribeiro, em Campos dos Goytacazes-RJ. Foram adquiridas dez goiabas, da cultivar Paluma, das quais as sementes foram extraídas, lavadas com cal hidratada e postas para secar à sombra. As sementes foram tratadas com Captan 500 TS $^{\circledR}$ na dose de 100 g. $\mathrm{kg}^{-1}$ do produto comercial e, posteriormente, foram armazenadas em geladeira por duas semanas.

Na primeira fase do trabalho, foi efetuada a semeadura e o preparo de miniestacas a partir dos despontes dos seedlings. A semeadura foi efetuada em duas bandejas, cada uma contendo 96 tubetes de $50 \mathrm{~cm}^{3}$ de volume. Em uma das bandejas, foi utilizado o substrato Plantmax ${ }^{\circledR}$ e na outra o substrato Amafibra ${ }^{\circledR}$. Foram colocadas três sementes por tubete, e a germinação teve início 19 dias após a semeadura. Quarenta e três dias após a semeadura, foi efetuado o desbaste, deixando-se uma plântula por tubete e, ao mesmo tempo, foi efetuada a repicagem de plântulas excedentes para outros tubetes. Aos 82 e 118 dias após a semeadura, foram avaliados o número de folhas e a altura das plantas. Aos 118 dias após a semeadura, as plantas cultivadas no substrato Plantmax ${ }^{\circledR}$ e no substrato Amafibra ${ }^{\circledR}$ atingiram médias de 8,79 cm e 5,21 cm de altura e 6 a 5 pares de folhas por planta, respectivamente. As partes apicais dos seedlings foram retiradas para o preparo das miniestacas. Os primórdios foliares foram descartados, por apresentarem tecido muito tenro, e as miniestacas foram preparadas com a parte restante, com dois nós, independentemente do seu comprimento. O par de folhas basal da miniestaca foi retirado e, no par de folhas superior, o limbo foi reduzido à metade. As miniestacas provindas dos dois tipos de substratos foram postas, individualmente, em tubetes com volume de $180 \mathrm{~cm}^{3}$, preenchidos com substrato Plantmax ${ }^{\circledR}$, sendo 210 estacas no total, e colocadas em disposição aleatória em câmara de nebulização intermitente, por 40 dias. O ambiente foi controlado por microaspersões com duração de 10 segundos e repetidas a cada 15 minutos. Quarenta dias após o estaqueamento, verificou-se que $76 \%$ das miniestacas enraizaram e emitiram parte aérea. Após esse período, foram avaliados o diâmetro, o comprimento e a massa fresca das miniestacas; o comprimento, a massa fresca e o número de brotações da parte aérea, e o comprimento, a massa fresca e o número de raízes. As miniestacas enraizadas foram agrupadas dentro de sete classes de comprimento, as quais compuseram os tratamentos: T1: $12,00-16,00 \mathrm{~mm}$; T2: 16,01-20,00 mm; T3: 20,01-24,00 mm; T4: 24,01-28,00 mm; T5: 28,01-32,0 mm; T6: 32,01-36,00 mm; T7:36,01$40,00 \mathrm{~mm}$. O efeito dos tratamentos (comprimento da miniestaca) foi avaliado em delineamento 
inteiramente casualizado, com número diferente de repetições com: 12; 11; 25; 27; 34; 27 e 24 estacas nos tratamentos: T1, T2, T3, T4, T5, T6 e T7, respectivamente. As médias de comprimento das miniestacas em cada classe foram de: 13,5; 18,6; 22,1; 26,3; 29,4; 34,1 e 37,9 mm. Os dados obtidos para número e massa de brotações da parte aérea foram transformados em $\sqrt{\mathrm{n} 0,5}$ para que seguissem distribuição normal, e submetidos às análises de variância e de regressão. Os dados obtidos, nessa fase, para o número, o comprimento e a massa fresca de raízes, foram submetidos a análises de variância e de regressão, sem necessidade de transformação. As curvas foram ajustadas entre as médias de comprimento das miniestacas, obtidas em cada classe de tamanho, e as médias das características avaliadas.

Na segunda etapa do trabalho, foi avaliada a rebrota dos seedlings que foram anteriormente despontados, e novas miniestacas foram produzidas com as brotações laterais. Sete dias após o desponte dos seedlings, constatou-se o começo da rebrota, dando-se começo à formação de minitouceiras. As minitouceiras foram avaliadas quanto a sua capacidade de rebrota 39 dias após o desponte. Avaliaram-se o número de brotações por minitouceira e o comprimento médio e o número médio de folhas por brotação. As novas brotações foram coletadas, e destas, preparadas 30 novas miniestacas. O novo estaqueamento foi feito em câmara de nebulização, nas mesmas condições descritas anteriormente para enraizamento das primeiras miniestacas coletadas. Aos 35 dias após o estaqueamento, foram avaliados o comprimento, o diâmetro e a massa fresca das miniestacas; o comprimento, o número e a massa fresca das brotações das miniestacas, e o número, o comprimento e a massa fresca das raízes emitidas pelas miniestacas. Das 30 miniestacas avaliadas, 63,3\% apresentaram início de brotação da parte aérea aos 35 dias após o estaqueamento.

Na Figura 1, são apresentados o diâmetro e a massa fresca das miniestacas produzidas na primeira etapa do trabalho. De modo geral, estacas de maior comprimento médio apresentaram maior diâmetro e, consequentemente, maior massa. Esses dados evidenciam que o maior comprimento não ocorreu em função de estiolamento, o qual, segundo Costa Jr. et al. (2003), pode interferir no enraizamento de estacas da goiabeira.

O comprimento médio da miniestaca influenciou na brotação da parte aérea. Estacas de menor comprimento apresentaram maior massa e tamanho de brotações da parte aérea, dentro do intervalo estudado (Figura 2). Entretanto, estacas de maior comprimento do caule resultaram em maior comprimento e massa fresca de raízes (Figura 3). O comprimento da miniestaca não influenciou no número de raízes que, em média, foi de 2,51 por miniestaca.

Na segunda etapa do trabalho, verificou-se que os seedlings da goiabeira que forneceram as primeiras miniestacas, apresentaram início de rebrota sete dias após desponte. Aos 32 dias após início da rebrota, constatou-se que $57,2 \%$ das mudas apresentavam duas brotações e $42,8 \%$ apresentavam somente uma brotação. Houve tendência de dominância de uma brotação sobre a outra, e estas apresentaram diferenças entre si, na altura, no número de folhas e no tamanho do internódio. O número médio de brotações, a altura média $(\mathrm{cm})$, o número médio de folhas e o tamanho médio do internódio (cm) de 160 minitouceiras avaliadas foram de 1,52 \pm 0,$43 ; 2,02 \pm 1,06 ; 5,86 \pm 1,75$ e $0,49 \pm 0,22$, respectivamente.

A capacidade de produção das minitouceiras é uma característica importante para a propagação por miniestaquia. Para multiplicação de espécies do gênero Eucalyptus, os sistemas de produção influenciam na quantidade de miniestacas produzidas e no intervalo de coleta. Segundo Wendling (2002), são produzidas, em média, 1,9 miniestaca por minitouceira, a cada 20 dias, para o eucalipto conduzido no sistema de minijardim clonal em tubetes. A média de 1,52 brotação por minitouceira, encontrada no presente trabalho, indica capacidade de rebrota necessária para miniestaquia. Segundo Cunha et al. (2005), na primeira coleta em minitouceiras do Eucalyptus benthamii, verificou-se menor produção de miniestacas em relação às coletas posteriores. Neste trabalho, os dados de produção foram avaliados apenas na primeira coleta, realizada aos 32 dias após desponte das minicepas.

As médias do comprimento (mm), do diâmetro (mm) e da massa fresca (g) das miniestacas fornecidas pelas novas brotações das minitouceiras, aos 35 dias após o estaqueamento, foram de 13,56 $\pm 3,31 ; 1,45 \pm$ 0,26 e $0,079 \pm 0,022$, respectivamente. O comprimento médio de 13,56 mm das miniestacas da segunda coleta situou-se dentro da primeira classe de comprimento das miniestacas obtidas na primeira coleta. Essas miniestacas apresentaram $100 \%$ de enraizamento. As brotações aéreas dessas miniestacas apresentaram médias de 2,21 \pm 0,63 folhas, 6,98 \pm 4,88 $\mathrm{mm}$ de comprimento e $0,018 \pm 0,015 \mathrm{~g}$ de massa fresca. $\mathrm{O}$ sistema radicular apresentou número médio de raízes de 2,57 $\pm 0,86$, comprimento total de 71,09 $\pm 35,41 \mathrm{~mm}$ e $0,047 \pm 0,022 \mathrm{~g}$ de massa fresca. 
A goiabeira pode ser propagada por miniestacas provenientes de seedlings. O desenvolvimento dessa tecnologia pode ser útil para avaliações preliminares de algumas características de interesse em programas de melhoramento da goiabeira, como, por exemplo, na seleção de genótipos resistentes a pragas e doenças .
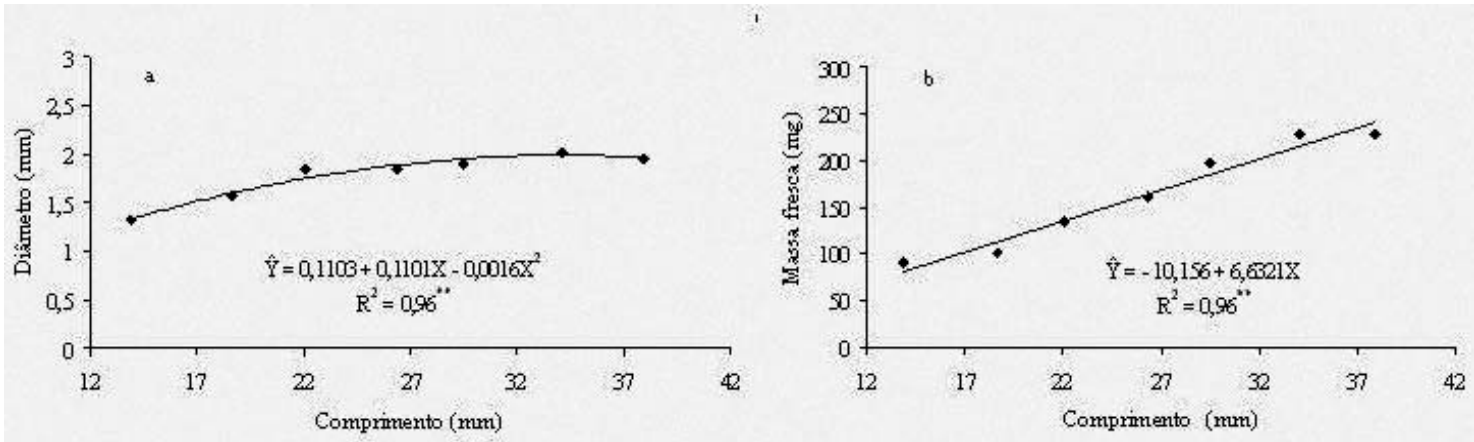

FIGURA 1. Diâmetro (a) e massa fresca (b) das miniestacas de goiabeira em função do comprimento médio das miniestacas da goiabeira 'Paluma’, aos 40 dias após estaqueamento.
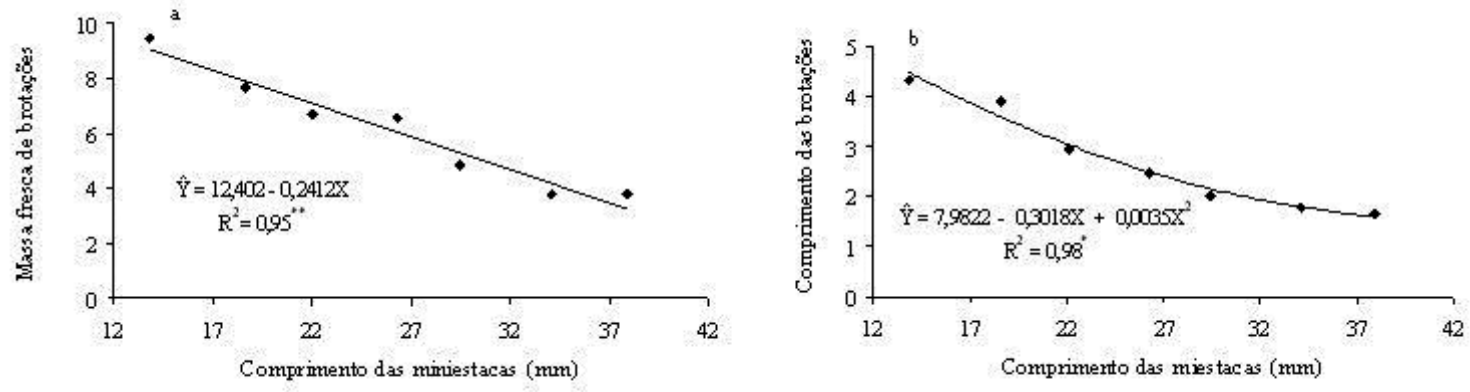

FIGURA 2 - Médias da massa fresca (a) e do comprimento (b) das brotações emitidas pelas miniestacas da goiabeira 'Paluma', aos 40 dias após estaqueamento, em função do comprimento médio da miniestaca. *Valores transformados em $\sqrt{\mathrm{n} 0,5}$, sendo “n” a massa fresca (mg) ou comprimento (mm).
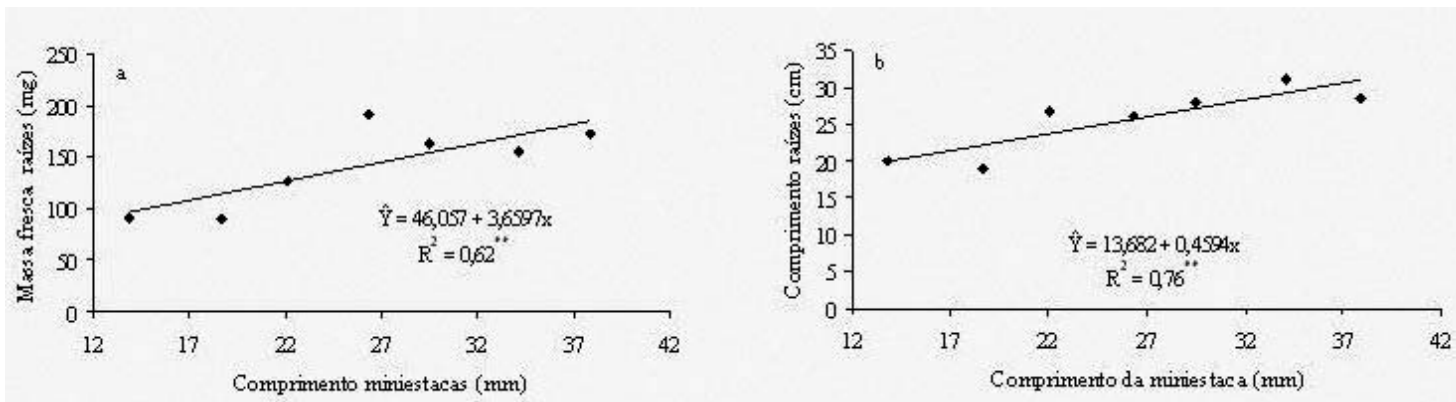

FIGURA 3- Médias da massa fresca (a) e do comprimento total (b) das raízes emitidas pelas miniestacas da goiabeira 'Paluma', aos 40 dias após estaqueamento, em função do comprimento médio da miniestaca. 


\section{REFERÊNCIAS}

ALFENAS, A.C.; ZAUZA, E.A.V.; MAFIA, R.G.; ASSIS, T.F. Clonagem e doenças do eucalipto. Viçosa; UFV, Imprensa Universitária, 2004 p.442.

ANDREJOW, G.M.P. Minijardim clonal de Pinus taeda L. 2006. 92 f. Dissertação (Mestrado em Engenharia Florestal) - Universidade Federal do Paraná, Curitiba, 2006.

COSTAJR, W.H.; SCARPARE FILHO, J.A.; BASTOS, D.C. Estiolamento da planta-matriz e uso de ácido indolbutírico no enraizamento de estacas de goiabeiras. Revista Brasileira de Fruticultura, Jaboticabal, v.25, n.2, p.301-304, 2003.

CUNHA, A.C.M.C.M.; WENDLING, I.; SOUZA JR, L. Produtividade e sobrevivência de minicepas de Eucaliptus benthamii Maiden et Cambage em sistema de hidroponia e em tubete. Ciência Florestal, Santa Maria, v.15, n.3, p.307-310, 2005.
WENDLING, I. Rejuvenescimento de clones de Eucalytus grandis por miniestaquia seriada e micropropagação. 2002. 98 f. Tese (Doutorado em Ciência Florestal) - Universidade Federal de Viçosa, Viçosa, 2006.

XAVIER, A.; SANTOS, G. A.; WENDLING, I.; OLIVEIRA, M. L. Propagação vegetativa de cedrorosa por miniestaquia. Revista Árvore, Viçosa, v.27, n. 2, p.139-143, 2003.

ZIETEMANN, C.; ROBERTO, S.R. Produção de mudas de goiabeira (Psidium guajava L.) em diferentes substratos. Revista Brasileira de Fruticultura, Jaboticabal, v. 29, n.1, p. 137142, 2007. 